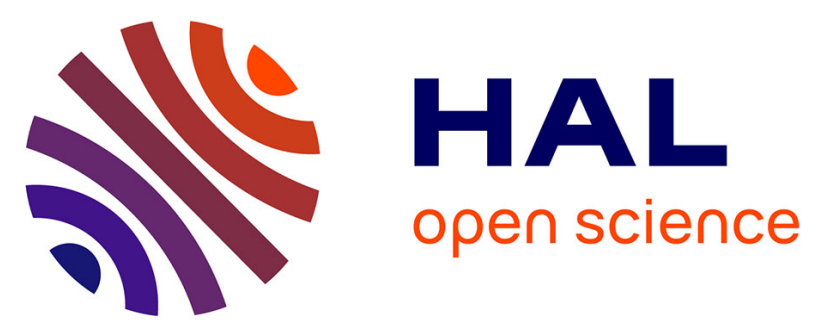

\title{
Occurrence of Atrial Fibrillation During Dobutamine Stress Echocardiography
}

Nicolas Mansencal, Hazrije Mustafic, Marie Hauguel-Moreau, Simon Lannou, Catherine Szymanski, Olivier Dubourg

\section{- To cite this version:}

Nicolas Mansencal, Hazrije Mustafic, Marie Hauguel-Moreau, Simon Lannou, Catherine Szymanski, et al.. Occurrence of Atrial Fibrillation During Dobutamine Stress Echocardiography. American Journal of Cardiology, 2019, 123, pp.1277 - 1282. 10.1016/j.amjcard.2019.01.022 . hal-03486661

\section{HAL Id: hal-03486661 \\ https://hal.science/hal-03486661}

Submitted on 20 Dec 2021

HAL is a multi-disciplinary open access archive for the deposit and dissemination of scientific research documents, whether they are published or not. The documents may come from teaching and research institutions in France or abroad, or from public or private research centers.
L'archive ouverte pluridisciplinaire HAL, est destinée au dépôt et à la diffusion de documents scientifiques de niveau recherche, publiés ou non, émanant des établissements d'enseignement et de recherche français ou étrangers, des laboratoires publics ou privés.

\section{(c)(1) $\$$}

Distributed under a Creative Commons Attribution - NonCommerciall 4.0 International 


\title{
Occurrence of Atrial Fibrillation
}

\section{During Dobutamine Stress Echocardiography}

Running head: Atrial Fibrillation and Dobutamine Stress Echocardiography

\author{
Nicolas Mansencal, MD, PhD ${ }^{\mathrm{a}, \mathrm{b}}$, Hazrije Mustafic, MD, $\mathbf{P h D}^{\mathrm{a}, \mathrm{b}}$, Marie Hauguel-Moreau, \\ $M^{a, b}$, Simon Lannou, MD ${ }^{a, b}$, Catherine Szymanski, MD, PhD ${ }^{a, b}$, Olivier Dubourg, MD $^{\mathrm{a}, \mathrm{b}}$
}

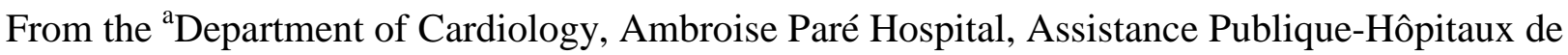
Paris (AP-HP), Centre de référence des cardiomyopathies et des troubles du rythme cardiaque héréditaires ou rares, Université de Versailles-Saint Quentin (UVSQ), Boulogne, France ${ }^{\mathrm{b}}$ INSERM U-1018, CESP, Team 5 (EpReC, Renal and Cardiovascular Epidemiology), UVSQ, Villejuif, France

The authors declare no conflict of interest

\section{Address for correspondence:}

Nicolas Mansencal, MD, PhD

AP-HP, Hôpital Universitaire Ambroise Paré

Service de Cardiologie

Centre de référence des cardiomyopathies et des troubles du rythme cardiaque héréditaires ou rares

9 avenue Charles de Gaulle

92100 Boulogne, France.

Phone number: $+33(0) 149095619$

Fax number: +33 (0)149095344

e-mail: nicolas.mansencal@apr.aphp.fr 


\begin{abstract}
Dobutamine stress echocardiography (DSE) is a widely used examination for assessment of coronary ischemia, but several complications have been reported. The aim of this study was to assess the incidence of atrial fibrillation (AF) during DSE and a systematic review and metaanalysis were also performed to determine an accurate estimate of the AF incidence. Over a 16year period, we reviewed all patients referred for DSE. We systematically analyzed all ECG performed during DSE to detect AF during the examination. DSE was completely performed in 4818 patients (mean age: $62.1 \pm 11.7$ years). AF was observed in 40 patients ( 31 men, mean age: $79.7 \pm 8.9$ years). Incidence of AF during DSE was $0.83 \%$. Regarding the meta-analysis, the combined AF incidence was $0.86 \%$. In our study, patients with AF occurrence had more frequent previous history of paroxysmal AF $(\mathrm{p}=0.02)$, were also older $(\mathrm{p}<0.0001)$ and incidence of AF during DSE increased with age: $0 \%$ below 60 years, $0.45 \%$ in patients $60-69$ years, $1.3 \%$ in patients $70-79$ years and $4 \%$ in patients $>80$ years $(\mathrm{p}<0.0001)$. In multivariate analysis, the factors significantly associated with an increased risk of AF were age (aOR $=2.4,95 \% \mathrm{CI}: 1.5-$ 3.3, $\mathrm{p}=0.003)$ and previous history of paroxysmal AF $(\mathrm{aOR}=1.5,95 \% \mathrm{CI}: 1.1-1.9 ; \mathrm{p}=0.04)$. In conclusion, $\mathrm{AF}$ is uncommon during DSE, and elderly patients and patients with previous history of paroxysmal AF are at risk of AF during DSE.
\end{abstract}

Keywords: atrial fibrillation; dobutamine stress echocardiography; complications; side effect, meta-analysis. 
Dobutamine stress echocardiography (DSE) is routinely performed for the assessment of coronary ischemia, with an excellent diagnostic and prognostic value. Despite its wide use, several complications or side effects of DSE have been reported: myocardial infarction, supraventricular or ventricular arrhythmias, hypotension, coronary spasm and death. ${ }^{1,2}$ Thus, atrial fibrillation (AF) may occur during DSE, but studies for the incidence of this specific side

effect of DSE remain rare. ${ }^{3-30}$ The aim of this study was to assess the incidence of AF during DSE and to pool it with the AF incidence during DSE of all other published studies, in order to determine an accurate estimate with an aggregated incidence.

\section{Methods}

Over a 16-year period (from November 2001 to October 2017), we reviewed all consecutive patients $(n=4917)$ referred for DSE. Entry criteria included age $>18$ years and all patients who underwent DSE. Patients presenting with permanent or persistent AF were not included in this study. All DSE were performed by a medical doctor. We distinguished patients presenting with normal DSE (no significant symptoms, no ECG modifications nor wall motion abnormalities during examination) from patients presenting with positive DSE, according to guidelines. All patients had an ECG monitoring during DSE and we systematically analyzed all ECGs performed during the echocardiographic examination, thus identifying occurrence of atrial fibrillation (> 5 seconds). All echocardiographic examinations were performed using a Siemens/Sequoia Acuson C512 system (Acuson, Mountain View, CA, USA) or a Vivid 7 or 9 system (GE Medical Systems, Horten, Norway), equipped with multifrequency transducers and capable of low energy ( 0.2 to 0.3 mechanical index). In the case of suboptimal acoustic windows, left ventricular cavity opacification was performed by peripheral venous injection of Sonovue ${ }^{\circledR}$ contrast agent (Bracco 
Altana Inc, Milan, Italy). Dobutamine was administered intravenously in an incremental regimen of 10, 20, 30 and $40 \mu \mathrm{g} / \mathrm{kg} / \mathrm{min}$ every 3 minutes for each dose (from 2001 to 2004) and every 2 minutes after this first period. Atropine $(0.25-1 \mathrm{mg})$ was administered at the beginning of 20,30 and $40 \mu \mathrm{g} / \mathrm{kg} / \mathrm{min}$ of dobutamine (in case of non-contraindication) and DSE was stopped when the target heart rate [85\% of the predicted maximal heart rate (220- age (years)] was achieved. Without contraindication, intravenous beta-blockers were performed at the end of DSE. Dobutamine stress echocardiography was interpreted according to guidelines.

Continuous variables were compared using Student's test. Categorical data are compared using the chi-square test, Fisher's exact test or Wilcoxon test as appropriate. We performed a multivariate logistic regression analysis to identify sets of factors that together are significantly associated with the occurrence of AF. All the tests were two-sided and the results were considered significant at $p<0.05$. Statistical analysis was performed with STATA 12.0 (StataCorp, College Station, TX). To further determine an accurate estimate of the AF incidence during DSE, we performed a meta-analysis. A previous literature review was published in 2010, but the combined incidence of AF during DSE was not calculated. ${ }^{1}$ Moreover, this review was not exhaustive and since 2010 other studies have been published. Our meta-analysis complies with the preferred reporting items of PRISMA for systematic reviews and meta-analyses. A comprehensive search of several electronic databases (between 1948 and August 26, 2018) was conducted in EMBASE between 1988 and August 26, 2018; Ovid MEDLINE in-process and other non-indexed citations and Ovid MEDLINE between 1948 and August 26, 2018; and EBM Reviews-Cochrane Central Register of Controlled Trials and EBM Reviews-Cochrane Database of Systematic Reviews between 2005 and August 26, 2018. In addition, we searched the reference lists of relevant studies and reviews for additional published and unpublished data and used the web search engine "Google" for abstracts, conference proceedings, and unpublished 
studies. We used a combination of keywords related to the type of exposure ("dobutamine stress echocardiography") and to the type of outcome ("atrial fibrillation"). The studies involved adults and could be of any design and any language. We excluded animal studies, ex vivo and toxicological studies, duplicates, summaries, commentaries, editorials, case reports, studies that did not evaluate AF incidence during DSE and studies without original data. Two independent reviewers (N.M. and H.M.) screened all abstracts and titles to identify potentially eligible studies. The full text of these potentially eligible studies was then screened to determine the eligibility of the study for the review and meta-analysis. Disagreements regarding eligibility were resolved by consensus. Data extraction using a standardized form included a full description of the study characteristics. Incidences were reported in percentage with $95 \%$ confidence interval (CI) and the combined incidence was estimated using a random-effects model. This model was chosen because of anticipated significant heterogeneity between studies in terms of population and methods. The random-effects model is the most conservative approach in this setting because it incorporates within and between-study heterogeneity in the CI. Statistical heterogeneity across the studies was calculated by the $\mathrm{I}^{2}$ statistics to quantify inconsistencies between studies. $\mathrm{I}^{2}$ values $<25 \%, 25 \%-50 \%, 50 \%-75 \%$ and $>75 \%$, respectively represent low, moderate, high and very high inconsistency. To assess the potential for publication bias, we added the Egger's regression test P-value for funnel symmetry, a p-value $<0.05$ is an argument for a potential publication bias. All analyses were performed with Comprehensive Meta-analysis software, version 2.0 (Biostat, USA).

\section{Results}


Among 4917 patients referred for DSE in our institution, 4818 patients (3592 [76\%] men) underwent complete DSE (Figure 1). Mean age was 62.1 \pm 11.7 years. Dobutamine stress echocardiography was considered as positive in 1535 patients and negative in 3283 patients. Atrial fibrillation occurred in 40 patients (31 men, mean age: $79.7 \pm 8.9$ years). Incidence of AF during DSE was $0.83 \%$ (95\% CI: 0.57-1.09) and was similar whatever the result of DSE (0.85\% in case of positive DSE versus $0.82 \%$ in case of negative DSE, $\mathrm{p}=0.93$ ). Atrial fibrillation occurred with $40 \gamma / \mathrm{kg} / \mathrm{min}$ of dobutamine in 29 patients $(72.5 \%)$ versus with $30 \gamma / \mathrm{kg} / \mathrm{min}$ of dobutamine in 6 patients (15\%), with $20 \gamma / \mathrm{kg} / \mathrm{min}$ of dobutamine in 2 patients (5\%) and in early recovery in 3 patients $(7.5 \%)$. The use of atropine was similar in the 2 groups of patients (Table 1). Several patient characteristics were univariately associated with the occurrence of AF (Table 1). Atrial fibrillation during DSE was significantly more frequent in patients with previous history of paroxysmal AF $(\mathrm{p}=0.02)$. Patients with AF occurrence were also significantly older $(p<0.0001)$ and incidence of AF during DSE increased with age: $0 \%$ below 60 years, $0.45 \%$ in patients 60 to 69 years, $1.3 \%$ in patients 70 to 79 years and $4 \%$ in patients $>80$ years $(\mathrm{p}<0.0001)$. In multivariate analysis, the factors significantly associated with an increased risk of AF during DSE were age $(\mathrm{aOR}=2.4,95 \% \mathrm{CI}: 1.5-3.3, \mathrm{p}=0.003)$ and previous history of paroxysmal AF $(\mathrm{aOR}=1.5,95 \% \mathrm{CI}: 1.1-1.9 ; \mathrm{p}=0.04)$

Dobutamine infusion was immediately discontinued in case of AF. Duration of AF was less than one hour in most of patients $(67.5 \%)$ with spontaneous termination of AF (Table 2). For the 13 patients with duration of AF higher than one hour and after anticoagulation, pharmacological cardioversion (amiodarone or flecainide) was systematically attempted and only $7.5 \%$ had persistent AF. For those patients, an electrical cardioversion was performed at distance and all patients had a recovery of sinus rhythm. 
Regarding the meta-analysis, the search strategy on the mentioned electronic databases, identified 199 citations to which we added 3 citations from reference lists of relevant studies and reviews. After screening titles, abstracts, 35 citations were considered potentially eligible and the full-text article was retrieved. Of those, 7 citations were excluded, resulting in 28 selected studies to which we added our present study (Figure 2) ${ }^{3-30}$ Thus, we calculated a combined incidence of AF during DSE from a total of 29 studies. Interrater agreement for study selection was very high between the two reviewers. The number of DSE performed per study ranged between 63 and 11806, the number of AF incident cases ranged between 1 and 122. AF incidence during DSE ranged from $0.29 \%$ to $2 \%$ and this incidence was investigated in several sites on every continent from 1990 to 2017. The combined incidence of AF during DSE was 0.86\% (95\% CI: 0.70-1.02), the statistical heterogeneity across the studies was high $\left(I^{2}=71.5 \%\right)$ but expected and there was no statistical argument for any publication bias (Egger's regression test $\mathrm{p}=0.15$ ) (Figure 3).

\section{Discussion}

The main results of the present study were: 1) atrial fibrillation during DSE is uncommon (our study incidence was $0.83 \%$ and of the same magnitude order as the combined incidence of the meta-analysis); 2) age and previous history of paroxysmal $\mathrm{AF}$ are predictive factors of $\mathrm{AF}$ occurrence; 3) most of AF are paroxysmal and cardioversion is rarely performed.

DSE is a routine test performed for the diagnosis of coronary artery disease because of its accuracy. Its indications have increased notably these last years, leading to more DSE tests and consequently more side effects. Several complications or side effects of DSE may occur. ${ }^{1}$ The most frequent complications are hypertension, hypotension and induced arrhythmias. However, other less frequent complications may occur, such as myocardial infarction, coronary artery 
spasm, and death. Occurrence of AF is a potential side effect of DSE. Dobutamine acts directly through $\beta$-adrenergic receptor activation, leading to increase the risk of AF through enhancement of intracellular 3'-5' -cyclic adenosine monophosphate. In the present study, we found an incidence of $0.83 \%$ and very close to the aggregated incidence of AF in our meta-analysis, confirming that AF during DSE remains uncommon. The heterogeneity between the studies was very high but expected because of the different methodologies used, the analyzed populations also were different in terms of age, sex, history of AF, high blood pressure. There was no statistical argument for a publication bias and therefore the estimate by the aggregated incidence must be pretty close to the real incidence.

We found that the main factor associated with AF occurrence during DSE is age. The incidence of AF significantly increased with age $(0 \%$ in patients $<60$ years versus $4 \%$ in patients $\geq 80$ years). Previous history of paroxysmal AF is also a predictive factor of AF during DSE. Physicians should be aware of these interactions between AF and elderly patients and previous history of AF, should discuss the utility of this specific examination and could eventually propose another ischemic test with less risk of AF.

The occurrence of AF during DSE is usually associated to a prompt and fast recovery of sinus rhythm in most of patients $(<1$ hour), with discontinuation of dobutamine infusion and intravenous betablockers. For the remaining patients with AF $>1$ hour (32.5\%), an attempt to restore sinus rhythm with antiarrhythmic agents was performed and finally only $7.5 \%$ of our patients had $\mathrm{AF}>1$ day. These remaining patients had persistent $\mathrm{AF}$ and we performed electrical cardioversion, allowing to restore sinus rhythm. Thus, at distance, with adequate and conventional management, no patient had persistent AF secondary to DSE.

The limits of our study are that only 40 patients presented with AF during 4818 complete DSE. However, this population was in sinus rhythm and no patient was in atrial fibrillation at the 
beginning of DSE. Thus, we were able to clearly identify AF occurrence during DSE. This sideeffect of high-level of dobutamine infusion remains uncommon and we demonstrate that elderly patients and patients with previous history of paroxysmal AF are at risk of AF during DSE. 
1. Geleijnse ML, Krenning BJ, Nemes A, van Dalen BM, Soliman OI, Ten Cate FJ, Schinkel AF, Boersma E, Simoons ML Incidence, pathophysiology, and treatment of complications during dobutamine-atropine stress echocardiography. Circulation 2010;121:1756-1767.

2. Mansencal N, El Hajjaji I, El Mahmoud I, Digne F, Dubourg O. Prevalence of coronary artery spasm during dobutamine stress echocardiography. Am J Cardiol 2012;109:800804.

3. Mertes H, Sawada SG, Ryan T, Segar DS, Kovacs R, Foltz J, Feigenbaum H. Symptoms, adverse effects, and complications associated with dobutamine stress echocardiography: experience in 1118 patients. Circulation 1993;88:15-19.

4. Poldermans D, Fioretti PM, Boersma E, Forster T, van Urk H, Cornel JH, Arnese M, Roelandt RT. Safety of dobutamine-atropine stress echocardiography in patients with suspected or proven coronary artery disease. Am J Cardiol 1994;73:456-459.

5. Fetiveau R, Lanzarini L, Poli A, Diotallevi P, Mussini MF, Montemartini C, Previtali M. The side effects and safety of the echo-dobutamine test. The experience with 373 patients [in Italian]. G Ital Cardiol 1995;25:193-201.

6. Cornel JH, Balk AH, Boersma E, Maat AP, Elhendy A, Arnese M, Salustri A, Roelandt JR, Fioretti PM. Safety and feasibility of dobutamine-atropine stress echocardiography in patients with ischemic left ventricular dysfunction. J Am Soc Echocardiogr 1996;9:27-32.

7. Zahn R, Lotter R, Nohl H, Schiele R, Bergmeier C, Zander M, Seidl K, Senges J. Feasibility and safety of dobutamine stress echocardiography: experiences with 1,000 studies [in German]. Z Kardiol 1996;85:28-34

8. Yeo TC, Ng WL, Ling LH, Chai P, Yeoh JK, Choo MH. Dobutamine stress echocardiography in the elderly Asian patients. Ann Acad Med Singapore 1997;26:165167. 
9. Secknus MA, Marwick TH. Evolution of dobutamine echocardiography protocols and indications: safety and side effects in 3,011 studies over 5 years. J Am Coll Cardiol 1997;29:1234-1240.

10. Pinton R, Lemke W, Garcia LG. Symptoms, complications and hemodynamic changes related to dobutamine stress echocardiography [in Portuguese]. Arq Bras Cardiol 1997;69:161-164.

11. Lamisse N, Cohen A, Chauvel C, Benhalima B, Désert I, Buyukoglu B, Blanchard B, Albo C, Boccara F, Valty J. Dobutamine stress echocardiography: a monocentric experience on 600 consecutive patients: effect of age [in French]. Arch Mal Coeur Vaiss 1997;90:1455-1461.

12. Hennessy TG, Codd MB, Kane G, McCarthy C, McCann HA, Sugrue DD. Safety of dobutamine stress echocardiography in 474 consecutive studies. Coron Artery Dis $1997 ; 8: 175-178$.

13. Bremer ML, Monahan KH, Stussy VL, Miller FA Jr, Seward JB, Pellikka PA. Safety of dobutamine stress echocardiography supervised by registered nurse sonographers. $J$ Am Soc Echocardiogr 1998;11:601-605

14. Pezzano A, Gentile F, Mantero A, Morabito A, Ravizza P. RITED (Registro Italiano Test Eco-Dobutamina): side effects and complications of echo-dobutamine stress test in 3041 examinations . G Ital Cardiol 1998;28:102-111.

15. Elhendy A, van Domburg RT, Bax JJ, Roelandt JR. Relation between the extent of coronary artery disease and tachyarrhythmias during dobutamine stress echocardiography. Am J Cardiol 1999;83:832-835.

16. Mathias W Jr, Arruda A, Santos FC, Arruda AL, Mattos E, Osório A, Campos O, Gil M, Andrade JL, Carvalho AC. Safety of dobutamine-atropine stress echocardiography: a 
prospective experience of 4,033 consecutive studies. J Am Soc Echocardiogr 1999;12:785-791.

17. Płońska E, Szwed H, Gasior Z, Drozdz J, Gackowski A, Szyszka A, Sieńko A, Flasiński J, Swiatkiewicz I, Sas M, Demczuk M, Kleinrok A, Krzymińska E. Side effects during dobutamine stress echocardiography: analysis of 582 studies [in Polish]. Pol Merkuriusz Lek 1999;7:164-168.

18. Takeuchi M, Miura Y, Sonoda S, Kuroiwa A. Comparison of three different protocols for dobutamine stress echocardiography: does the addition of atropine increase complications, and does it improve diagnostic accuracy? Echocardiography 1999;16:347-355.

19. Chenzbraun A, Khoury Z, Gottlieb S, Keren A. Impact of age on the safety and the hemodynamic response pattern during high dose dobutamine echocardiography. Echocardiography 1999;16:135-142.

20. Coisne D, Donal E, Torremocha F, Christiaens L, Allal J. Dobutamine stress echocardiography response of asymptomatic patients with diabetes. Echocardiography $2001 ; 18: 373-379$.

21. Cortigiani L, Picano E, Coletta C, Chiarella F, Mathias W, Gandolfo N, De Alcantara M, Mazzoni V, Gensini GF, Landi P; Echo Persantine International Cooperative (EPIC) Study Group; Echo Dobutamine International Cooperative (EDIC) Study Group. Safety, feasibility, and prognostic implications of pharmacologic stress echocardiography in 1482 patients evaluated in an ambulatory setting. Am Heart J 2001;141:621-629.

22. Tsutsui JM, Osório AF, Lario FA, Fernandes DR, Sodre G, Andrade JL, Ramires JA, Mathias W Jr. Comparison of safety and efficacy of the early injection of atropine during dobutamine stress echocardiography with the conventional protocol. Am J Cardiol 2004;94:1367-1372. 
23. Carasso S, Sandach A, Kuperstein R, Schwammenthal E, Glikson M, Luria D, Guetta V, Shechter M, Eldar M, Feinberg MS. Atrial fibrillation in dobutamine stress echocardiography. Int J Cardiol 2006;111:53-58.

24. Wejner-Mik P, Drozdz J, Lipiec P, Krzemińska-Pakuła M, Ciesielczyk M, Kasprzak JD. Prevalence of dangerous arrhythmia during pharmacological stress echocardiography [in Polish]. Pol Merkur Lekarski 2006;20:635-638.

25. San Román JA, Sanz-Ruiz R, Ortega JR, Pérez-Paredes M, Rollán MJ, Muñoz AC, Segura F, Jimenez D, Carnero A, Pinedo M, Arnold R, Gómez I, Fernández-Aviles F. Safety and predictors of complications with a new accelerated dobutamine stress echocardiography protocol. J Am Soc Echocardiogr 2008;21:53-57.

26. Mikheev NN. Complications of stress-echocardiography used for diagnosis of ischemic heart disease [Russian]. Kardiologiia 2008;48:19-23.

27. Aggeli C, Giannopoulos G, Roussakis G, Christoforatou E, Marinos G, Toli C, Pitsavos C, Stefanadis. Safety of myocardial flash-contrast echocardiography in combination with dobutamine stress testing for the detection of ischaemia in 5250 studies. Heart 2008;94:1571-1577.

28. Abdel-Salam Z, Nammas W. Early atropine is safer than conventional atropine administration in the elderly undergoing dobutamine stress echocardiography. Kardiol Pol 2010;68:422-428.

29. Sheldon SH, Askew JW 3rd, Klarich KW, Scott CG, Pellikka PA, McCully RB. Occurrence of atrial fibrillation during dobutamine stress echocardiography: incidence, risk factors, and outcomes. J Am Soc Echocardiogr 2011;24:86-90. 
30. Acharya Y, Agrawal S, Bhattarai J, Cotarlan V, Shirani J. Predictors and prognostic significance of atrial fibrillation developed during dobutamine stress echocardiography: A propensity score-matched comparison. Echocardiography 2017;34:429-435. 


\section{Figure legends}

Figure 1. Flowchart of patients in the study. DSE = dobutamine stress echocardiography.

Figure 2. A. Search strategy and study selection flowchart for the meta-analysis. B. Incidence of atrial fibrillation during dobutamine stress echocardiography -meta-analysis forest plot. AF $=$ atrial fibrillation; $\mathrm{CI}=$ confidence interval; DSE = dobutamine stress echocardiography . 
4917 patients referred for DSE

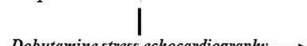

Dobutamine stress echocardiography

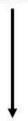

DSE not performed in 28 patients:

- Non-withdrawal of beta blockers: 15 patients

- Poor acoustic windows: 9 patients

- Refusal: 4 patients

4889 patients underwent DSE

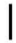

DSE not completely performed in 71 patients:

- Hypertension: 64 patients

- Ventricular arrhythmia: 7 patients

4818 patients underwent complete DSE |

Clinical presentation, ECG and echocardiographic results during test

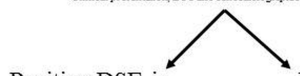

Positive DSE in

Negative DSE

1535 patients in 3283 patients

1

Atrial fibrillation

in 13 patients $(0.85 \%)$
Atrial fibrillation

in 27 patients $(0.82 \%)$

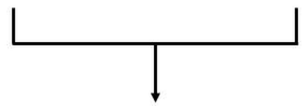

Occurrence of atrial fibrillation in 40 patients $(0.83 \%)$ 


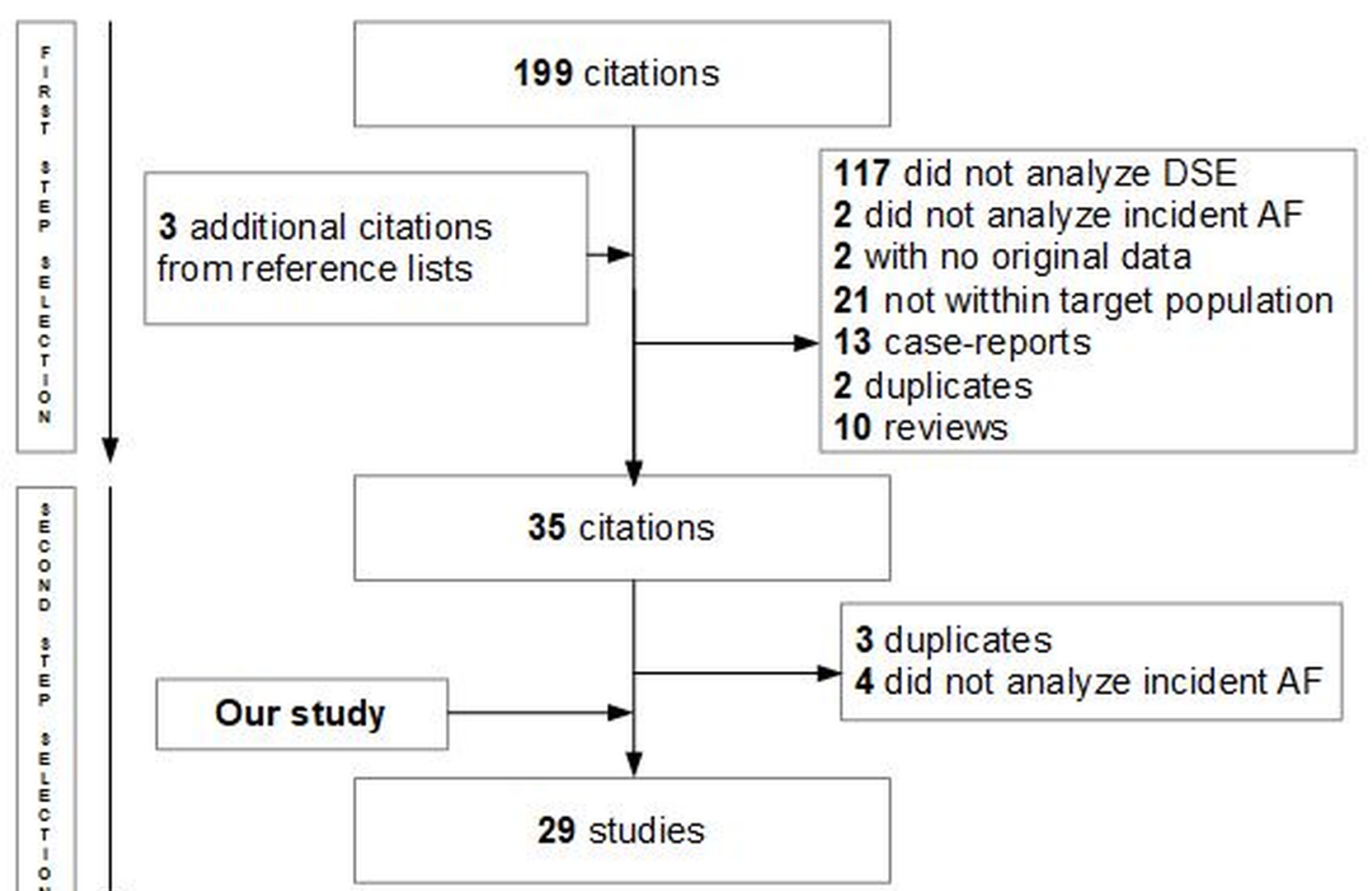


Study name

Mansencal 2018

Acharya 2017

Sheldon 2010

Abdel-Salam 2010

Aggeli 2008

Mikheev 2008

San Roman 2008

Wejner-Mik 2006

Carasso 2006

Tsutsui 2004

Cortigiani 2002

Coisnes 2001

Chenzbraun 1999

Mathias 1999

Plonska 1999

Elhendy 1999

Takeuchi 1999

Bremer 1998

Pezzano 1998

Hennessy 1997

Lamisse 1997

Pinton 1997

Secknus 1997

Yeo 1997

Zahn 1996

Cornel 1996

Fetiveau 1995

Poldermans 1994

Mertes 1993

Combined
AF incidence (\%) and $95 \% \mathrm{Cl}$

$\begin{array}{rrr}0,83 & 0,57 & 1,09 \\ 1,04 & 0,80 & 1,28 \\ 1,03 & 0,85 & 1,21 \\ 2,00 & -0,34 & 4,34 \\ 0,48 & 0,30 & 0,66 \\ 1,30 & -0,07 & 2,67 \\ 0,62 & 0,13 & 1,11 \\ 0,29 & -0,05 & 0,63 \\ 1,95 & 1,51 & 2,39 \\ 1,20 & 0,82 & 1,58 \\ 1,25 & 0,55 & 1,95 \\ 1,59 & -0,70 & 3,88 \\ 0,50 & -0,09 & 1,09 \\ 0,79 & 0,52 & 1,06 \\ 0,52 & -0,03 & 1,07 \\ 0,35 & -0,16 & 0,86 \\ 0,64 & 0,17 & 1,11 \\ 1,96 & 1,13 & 2,79 \\ 0,49 & 0,24 & 0,74 \\ 1,05 & 0,14 & 1,96 \\ 1,17 & 0,32 & 2,02 \\ 0,27 & -0,05 & 0,59 \\ 1,06 & 0,70 & 1,42 \\ 1,33 & -0,60 & 3,26 \\ 1,00 & 0,39 & 1,61 \\ 1,26 & 0,04 & 2,48 \\ 1,17 & -0,07 & 2,41 \\ 1,23 & 0,39 & 2,07 \\ 0,63 & 0,17 & 1,09 \\ \mathbf{0 , 8 6} & \mathbf{0 , 7 0} & \mathbf{1 , 0 2}\end{array}$

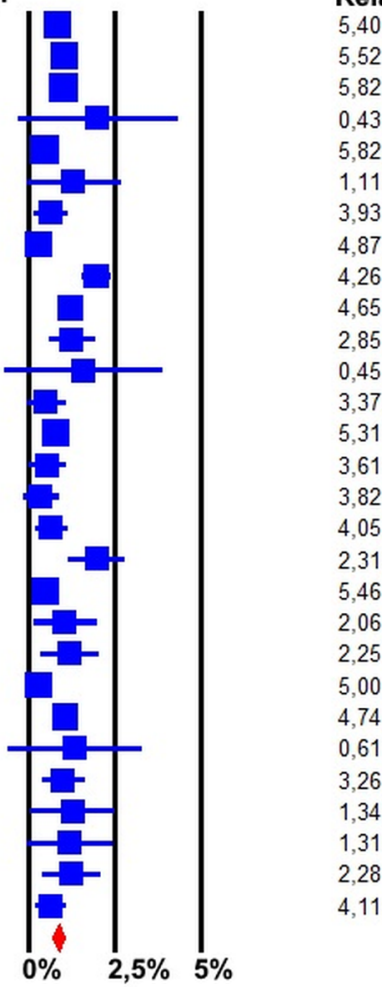

Relative weight

5,52

5,82

0,43

5,82

1,11

3,93

4,87

4,26

4,65

2,85

0,45

3,37

5,31

3,61

3,82

4,05

2,31

5,46

2,06

2,25

5,00

4,74

0,61

3,26

1,34

1,31

2,28

4,11

$\left(I^{2}=71,5 \%\right.$, Egger's regression test, $\left.P=0,15\right)$ 
Table 1. Characteristics of patients with complete DSE $(n=4818)$

\begin{tabular}{lccc}
\hline Variable & AF occurrence during DSE & P value \\
& No & Yes \\
$(\mathrm{n}=4778)$ & $(\mathrm{n}=40)$ & \\
\hline Age (years) & $62.0 \pm 11.6$ & $79.7 \pm 8.9$ & $<0.0001$ \\
Men & $3588(75 \%)$ & $31(78 \%)$ & 0.73 \\
Previous history of paroxysmal AF & $573(1 \%)$ & $10(25 \%)$ & 0.02 \\
\hline Cardiovascular risk factors & & & \\
Smoker & $1615(34 \%)$ & $13(32.5 \%)$ & 0.86 \\
Hypertension & $2435(51 \%)$ & $30(75 \%)$ & 0.17 \\
Diabetes mellitus & $514(11 \%)$ & $5(13 \%)$ & 0.72 \\
Dyslipidemia* & $1720(36 \%)$ & $15(38 \%)$ & 0.84 \\
\hline Echocardiographic measurements & & & \\
Left ventricular enddiastolic diameter (mm) & $51 \pm 6$ & $49 \pm 7$ & 0.64 \\
Left ventricular ejection fraction $(\%)$ & $60 \pm 7$ & $61 \pm 5$ & 0.92 \\
Left atrial volume (ml/m $\left.{ }^{2}\right)$ & $32 \pm 4$ & $35 \pm 7$ & 0.41 \\
\hline Dobutamine stress echocardiography & & & \\
Mean dosing of dobutamine $(\gamma / \mathrm{kg} / \mathrm{min})$ & $37 \pm 3$ & $38 \pm 2$ & 0.73 \\
Mean duration of examination $(\mathrm{min})$ & $12 \pm 2$ & $11 \pm 3$ & 0.86 \\
Use of atropine during examination & $4252(89 \%)$ & $35(88 \%)$ & 0.96 \\
Use of intravenous betablockers at the end of examination & $4526(95 \%)$ & $39(98 \%)$ & 0.72 \\
\hline AF: & &
\end{tabular}

AF: atrial fibrillation; DSE: dobutamine stress echocardiography

*Defined as high low-density lipoprotein cholesterol $\geq 4.14 \mathrm{mmol} / \mathrm{L}$ or patients treated with statin 
Table 2. Characteristics and outcome of DSE in 40 patients with atrial fibrillation

Heart rate according to dobutamine dose

At baseline

$67 \pm 12$

At $10 \gamma / \mathrm{kg} / \mathrm{min}$

$70 \pm 13$

At $20 \gamma / \mathrm{kg} / \mathrm{min}$

$77 \pm 17$

At $30 \gamma / \mathrm{kg} / \mathrm{min}$

$109 \pm 21$

At $40 \gamma / \mathrm{kg} / \mathrm{min}$

$147 \pm 27$

Systolic blood pressure according to dobutamine dose

At baseline

$149 \pm 18$

At $10 \gamma / \mathrm{kg} / \mathrm{min}$

$158 \pm 17$

At $20 \gamma / \mathrm{kg} / \mathrm{min}$

$159 \pm 25$

At $30 \gamma / \mathrm{kg} / \mathrm{min}$

$167 \pm 31$

At $40 \gamma / \mathrm{kg} / \mathrm{min}$

$170 \pm 26$

Diastolic blood pressure according to dobutamine dose

At baseline

At $10 \gamma / \mathrm{kg} / \mathrm{min}$

$75 \pm 11$

At $20 \gamma / \mathrm{kg} / \mathrm{min}$

$80 \pm 10$

At $30 \gamma / \mathrm{kg} / \mathrm{min}$

$76 \pm 11$

At $40 \gamma / \mathrm{kg} / \mathrm{min}$

$80 \pm 14$

Ischemia documented during DSE

$78 \pm 13$

Inferior or lateral wall ischemia

$13(32.5 \%)$

Septoapical or anterior wall ischemia

$9(69 \%)$

Duration of AF

$<1$ hour

$4(31 \%)$

$<24$ hours

$27(67.5 \%)$

Persistent ( $>7$ days, $<1$ month)

$10(25 \%)$

$3(7.5 \%)$

AF: atrial fibrillation; DSE: dobutamine stress echocardiography 